\title{
A Study to Evaluate the Effect of Hyperbaric Oxygen on Osseointegration of Root-form Endosseous Titanium Dental Implants: An In Vivo Study
}

\author{
Vamshi Krishna G ${ }^{1}$, Jayasree Komala ${ }^{2}$, Abdul HB Mohsin ${ }^{3}$, Mohd A Ahmed ${ }^{4}$, Gangishetti Sairam ${ }^{5}$, KV Sheethi $^{6}$
}

\begin{abstract}
Aim: To evaluate the effect of hyperbaric oxygen (HBO) therapy on the osseointegration of dental implants by resonance frequency analysis. Materials and methods: Six rabbits of age 2 to 2 and $1 / 2$ years, weight approximately $2 \mathrm{~kg}$ were selected and tagged $1-6$. For all the animals' right femur was selected as a control group ( $R$ ) and left femur as test group (L). Initially, implants of dimensions 3.75 $8 \mathrm{~mm}$ (Adin Touareg) were placed in the right femur. Implant stability quotient (ISQ) values were recorded using OSSTELL ISQ at the time of surgery $\left(R_{0}\right)$, after one month $\left(R_{1}\right)$, and the end of the second month $\left(R_{2}\right)$.

After two months of uneventful healing, implants were placed on the left femur of all the six rabbits and three were grouped as $2 S$ (subjected to $2 \mathrm{HBO}$ sessions at the weekly interval) and other three as $4 \mathrm{~S}$ (subjected to $4 \mathrm{HBO}$ sessions at weekly interval for a month). At the time of surgery $\left(\mathrm{L}_{0}\right)$, end of one month $\left(\mathrm{L}_{1}\right)$ and two months $\left(\mathrm{L}_{2}\right)$, ISQ values were recorded and subjected to statistical analysis. The total duration of the study was 4 months from 3 March 2013 to 03 July 2013.

Results: The data were statistically analyzed using t-test and analysis of variance (ANOVA) F. On the comparison between the control group (R) and test groups ( $2 \mathrm{~S}$ and $4 \mathrm{~S})$ ISQ values for test groups were more which was highly statistically significant $(p<0.001)$. Among the two test groups 4 S group has more ISQ values compared to $2 \mathrm{~S}(p<0.001)$.

Conclusion: This study indicated that $\mathrm{HBO}$ therapy has a promotive effect on the rate of osseointegration of dental implants.

Clinical significance: Study opens new scope for further in vivo research in utilizing hyperbaric oxygen therapy (HBOT) in implant surgeries, maxillofacial trauma cases and irradiated patients to hasten or improve osseointegration.

Keywords: Hyperbaric oxygen therapy, Hyperbaric oxygen therapy, Implant stability, Osseointegration, Resonance frequency analysis, Rabbit femur.
\end{abstract}

The Journal of Contemporary Dental Practice (2019): 10.5005/jp-journals-10024-2539

\section{INTRODUCTION}

mplants have been used to support dental prostheses for many decades. They are the nearest equivalent replacement to the natural tooth and are therefore a useful addition in the management of patients who have missing teeth because of disease, trauma or developmental anomalies.' The concept of osseointegration was given by Branemark on which the success of an implant treatment depends and is defined as direct structural and functional connection between ordered, living bone and the surface of a load-carrying implant. ${ }^{2}$ It has been advocated that after implant placement, surgical sites should be unloaded for at least 3-6 months to allow uneventful wound heali ng, thereby enhancing osseointegration between the implant and bone. ${ }^{3}$ The rationale behind this approach is that implant micromovement caused by functional force around the bone-implant interface during wound healing may induce fibrous tissue formation rather than the bone contact, leading to clinical failure. ${ }^{3}$ In addition, tissue coverage of an implant has also been thought to prevent infection and epithelial down growth. ${ }^{4,5}$ However, this discomfort, inconvenience, and anxiety associated with waiting period remains a challenge to both patients and clinicians.

Osseointegration can be hastened using surface treatments like surface etched, plasma sprayed surface, etc. ${ }^{6}$ All the methods mentioned in the literature focus on changing the surface the implant either by additive or subtractive methods. Another varied approach of enhancing osseointegration which is rapidly gaining importance in the field of dentistry is hyperbaric oxygen therapy
${ }^{1}$ Nehashine Hospital, Mahabubnagar, Telangana, India

${ }^{2}$ Department of Prosthodontics, SVS Institute of Dental Sciences, Mahabub Nagar, Telangana, India

${ }^{3}$ Department of Prosthodontics, Sri Sai College of Dental Surgery, Vikarabad, Telangana, India

${ }^{4}$ Dental Planet Multispeciality Dental Centre, Hyderabad, Telangana, India

${ }^{5}$ Department of Conservative Dentistry and Endodontics, Meghna Institute of Dental Sciences, Nizamabad, Telangana, India

${ }^{6}$ Department of Periodontics, Sri Sai College of Dental Surgery, Vikarabad, Telangana, India

Corresponding Author: Jayasree Komala, Department of Prosthodontics, SVS Institute of Dental Sciences, Mahabubnagar, Telangana, India, Phone: +919949270200, e-mail : jayasreekomala@yahoo.com

How to cite this article: Krishna VG, Komala J, Mohsin AHB, Ahmed MA, Sairam G, Sheethi KV. A Study to Evaluate the Effect of Hyperbaric Oxygen on Osseointegration of Root-form Endosseous Titanium Dental Implants: An In Vivo Study. J Contemp Dent Pract 2019;20(4): 460-465.

Source of support: Nil

Conflict of interest: None

(HBOT). The use of HBOT in enhancing wound healing has been tested over years ${ }^{7}$ and found to be effective.

Implant stability plays a critical role in successful osseointegration. Primary stability is the one which is measured at the time of implant placement itself; hence it is considered as

() The Author(s). 2019 Open Access This article is distributed under the terms of the Creative Commons Attribution 4.0 International License (https://creativecommons. org/licenses/by-nc/4.0/), which permits unrestricted use, distribution, and non-commercial reproduction in any medium, provided you give appropriate credit to the original author(s) and the source, provide a link to the Creative Commons license, and indicate if changes were made. The Creative Commons Public Domain Dedication waiver (http://creativecommons.org/publicdomain/zero/1.0/) applies to the data made available in this article, unless otherwise stated. 
mechanical stability. Secondary stability or biological stability develops over a while due to the healing process. Implant stability is always the sum of mechanical and biological, hence achievement and maintenance of implant stability are prerequisites for successful clinical outcome. Therefore, measuring the implant stability is an important method for evaluating the success of an implant. ${ }^{8}$ Various methods have been proposed to quantify implant stability, some are grouped as invasive (viz histological analysis, reverse torque test) and other as noninvasive methods (radiographic analysis, resonance frequency analysis RFA, etc.).

Resonance frequency analysis (RFA) has recently gained popularity, which is a noninvasive diagnostic method that measures implant stability and bone density at various time points using vibration and principle of structural analysis as based on early studies of Meredith. The principle of the resonance frequency is the most reliable in assessing implant stability clinically. ${ }^{6}$

RFA system contributed by Osstell Mentor ${ }^{\circledR}$ renders almost perfect reproducibility and repeatability, as proven by statistical analysis carried out by means of ICC with a $95 \%$ confidence level. This instrument contributes highly reliable RFA measurements in dental implants. ${ }^{9}$

The present study was done to evaluate the rapid healing effect of HBOT by using RFA (Osstell ISQ system) instrument. The null hypothesis was hyperbaric oxygen therapy does not have any effect on osseointegration.

\section{Material and methods}

The following study was conducted in Aptus Bioscience Pvt Ltd, SVS Medical College campus. Ethical clearance was obtained from the SVS Institute of Dental Sciences Institutional Ethics Committee on 28 November 2012.

Six Newzealand white male rabbits (Oryctolagus cuniculus) of age 2-2.5 years, weight approximately $2 \mathrm{~kg}$ were selected. RFAlnstrument (Osstell ISQ, Sweden) was used to determine implant stability, and HBOT therapy was given in HBOT chamber (Sechrist Monoplace Hyperbaric Chamber, US).

\section{Methodology}

- Mock procedure: Euthanized rabbit of Newzealand white breed was procured from Aptus Bio Labs. Right femoral bone was amputated completely at hip level to observe the anatomy. Radiographic analysis of the femoral bone was done, and a thorough discussion about various parameters of rabbit bone morphology and physiology was done with the local veterinarian, based on which age, sex, and weight of animals were selected for the study.

- Selection of animals and implants: Six healthy adult male Newzealand white breed rabbits of approximately 2-2.5 years age were selected. All the rabbits weighed approximately $2 \mathrm{~kg}$ and were tagged 1-6. Preoperative radiographs of the femur were taken and 12 Adin Touareg $\mathrm{S}$ dental implants of dimensions $3.75 \times 8 \mathrm{~mm}$ were selected for the procedure.

- Surgical procedure for implant placement: Surgical procedure was performed on 6 rabbits under the supervision of a veterinary surgeon.

- Preoperative preparation: Right femur was considered as a control for all the six rabbits and left femur as a test group. Furr over the femur was trimmed and shaved properly the day before surgery to expose the skin. Guaze dipped in betadine was placed over the exposed skin overnight till the time of surgery. All the rabbits were put on Nill Per Oral regime 6 hours before the surgical procedure. Preoperative prophylaxis was given 1 hour before the surgery with $1 \mathrm{gm}$ Cefotaxim IM and $50 \mathrm{mg}$ Diclofenac sodium IM.

- Anesthesia: A test dose of $0.1 \mathrm{~mL} / \mathrm{kg}$ body wt was administered to all the animals. The animals were anesthetized using intramuscular administration of Xylazine at a dose of $1 \mathrm{mg} / \mathrm{kg}$ body weight, diazepam at a dose of $0.5 \mathrm{~mL} / \mathrm{kg}$ body weight and ketamine hydrochloride at a dose of $2 \mathrm{mg} / \mathrm{kg}$ body weight mixed in a proportion of 1:2:1, respectively.

- Incisions: The surgery was performed under aseptic conditions. An incision was made on the skin of the lateral aspect of the right femur (Fig. 1A) using no.15 BP blade to expose underlying fascia. Another separate incision was made to open the fascial coverings over the muscle. The muscle spindles of muscle femorotibialis externus and biceps femori were divided to approach and expose a mid metaphyseal portion of the femur (Fig. 1B).

- Dental implant placement: Osteotomy site was prepared under profuse irrigation with saline solution with an initial $2 \mathrm{~mm}$ pilot drill followed by sequential drills of diameters $2.8 \mathrm{~mm}, 3.2 \mathrm{~mm}$, to a final diameter of $3.6 \mathrm{~mm}$ and length of $7 \mathrm{~mm} .3 .75 \times 8 \mathrm{~mm}$ implant (Adin Touareg) was placed in the prepared osteotomy site (Fig. 2) and torqued to $30 \mathrm{Ncm}$ (Fig. 3). Implants were placed in the right femur (control) of all the six rabbits following the same surgical procedure. All the implants were placed $1 \mathrm{~mm}$ supra crestal to have the advantage of recording ISQ values at a later time.
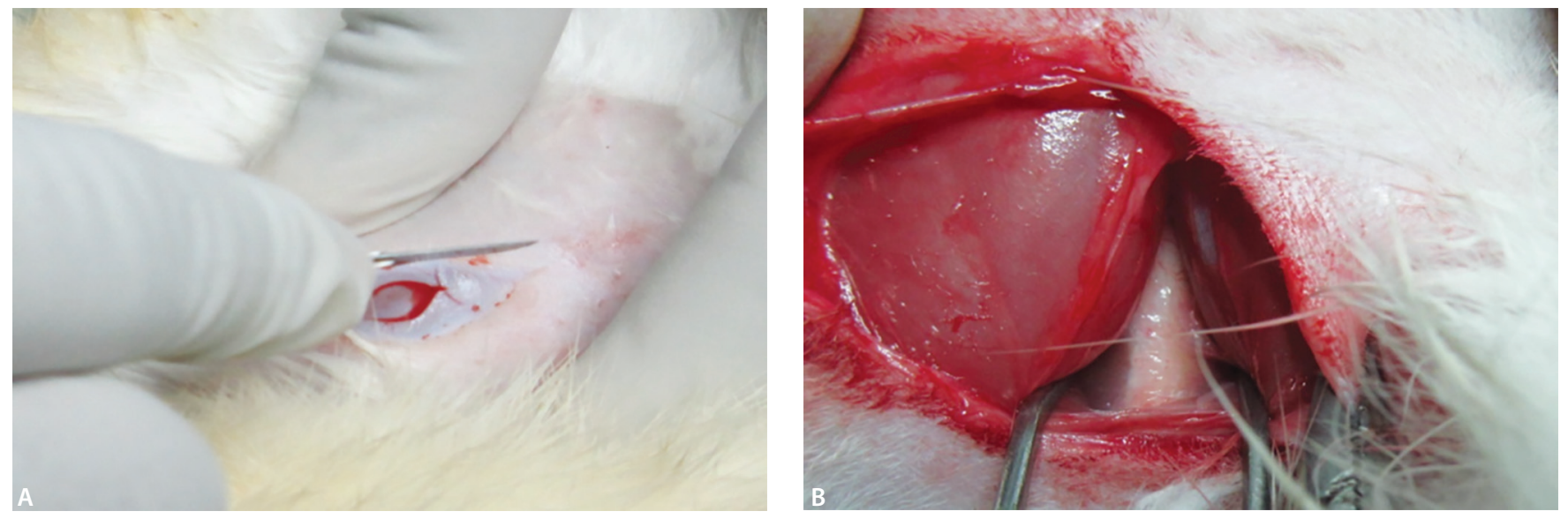

Figs 1 A and B: (A) Incision made on prepared femur; (B) Muscles femorotibialis externus and biceps femori divided 

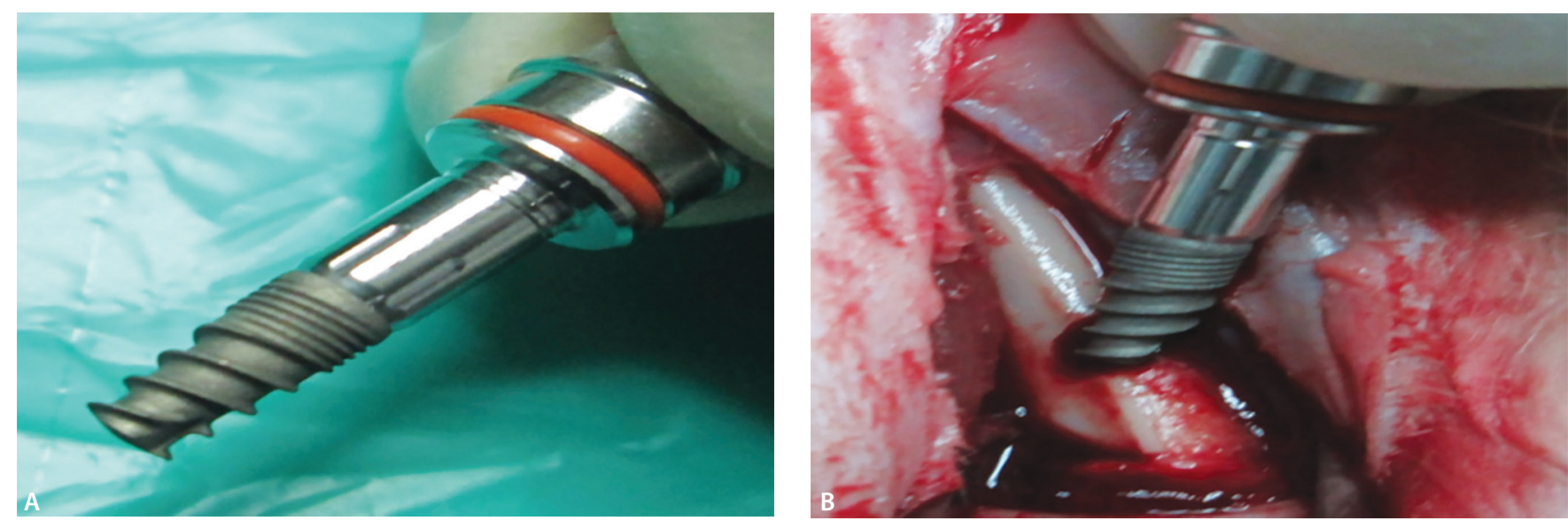

Figs 2A and B: (A) ADIN TOUREG 3.75DX8L; (B) Implant placement in osteotomy site

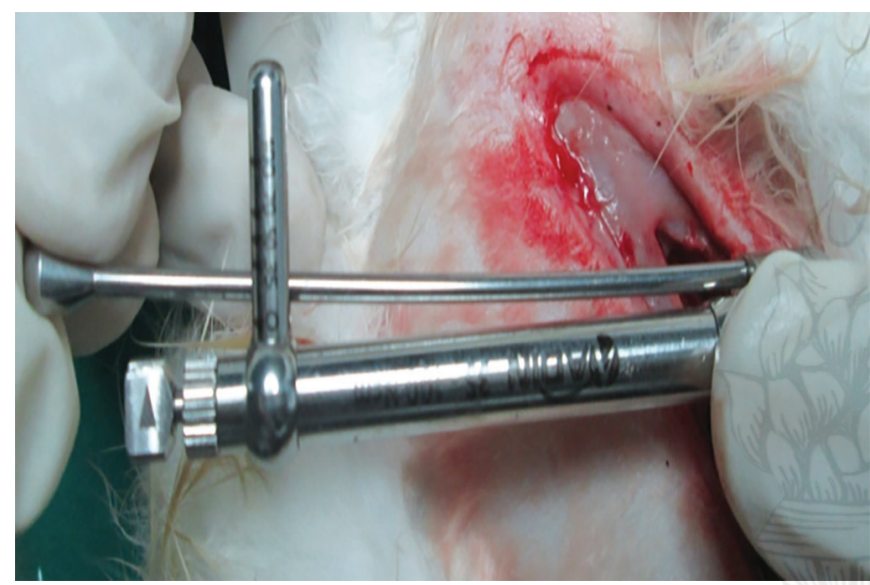

Fig. 3: $30 \mathrm{Ncm}$ torque

- Recording ISQ values: L-shaped transducer of osstell ISQ was tightened to the implant by a screw. Resonance peaks from received signal indicate the first resonance frequency of the measured object. This resonance peak was used to assess implant stability in a quantitative manner. Implant stability quotient ISQ values, R0 were recorded by placing smart peg (Fig. 4A) on the implant at the time of surgery with OSTELL ISQ (Fig.4B) on the implant at the time of surgery. Abutments were placed and incisions were sutured. Radiograph showing implant

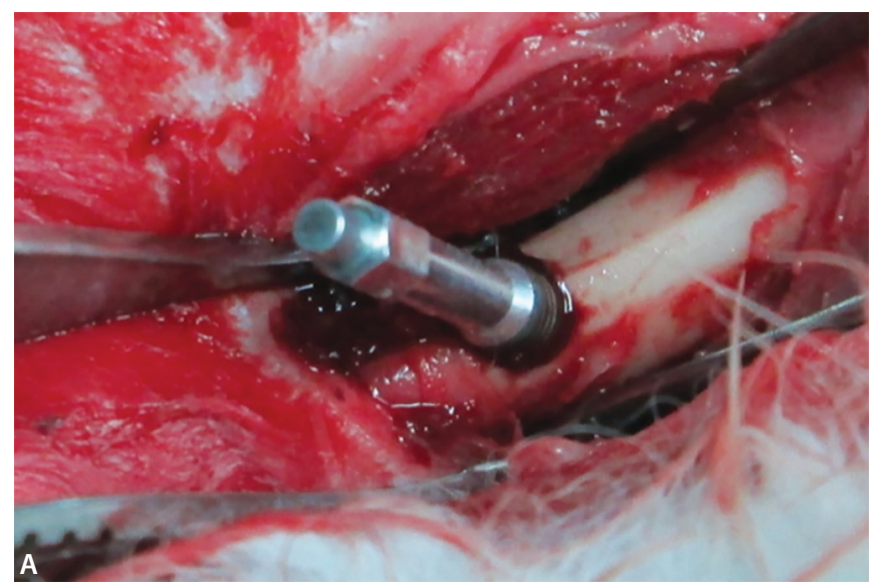

topography (Fig. 5). The prescribed dose of 1 gram Cefotaxime sodium IM $500 \mathrm{mg}$ twice daily for 3 days and $50 \mathrm{mg}$ diclofenac sodium IM twice daily for 3 days was administered.

ISQ values were recorded after one month $\left(R_{1}\right)$ and later at the end of the second month $\left(\mathrm{R}_{2}\right)$ and tabulated.

Surgical procedure for left leg(test group): After two months of first implantation procedure, the same osteotomy technique was followed and implants were placed in the left femur of all the six rabbits(test group) and were grouped into two, namely group $2 S$, rabbits with tags 1, 2, 3 were included in this group(subjected to $2 \mathrm{HBO}$ sessions) and rabbits with tags 4, 5, 6 were included in group $4 \mathrm{~S}$ (subjected to 4 HBOT sessions). Implant stability $\left(\mathrm{L}_{0}\right)$ was determined by RFA

Hyperbaric oxygen therapy (HBOT): All the animals were subjected to HBOT therapy immediately within 30 minutes of the osteotomy procedure. Each session of HBOT therapy consisted of subjecting the animal to $100 \%$ oxygen for 2 hours time at 1.5 atmp pressure in a closed chamber. The rabbits were placed in the chamber, and the door was closed. The oxygen was circulated, and this gradually caused an increase in pressure called compression. During this period, the first 15 minutes were used for successive compression up to $1.5 \mathrm{atmp}$ pressure, and the pressure was kept constant for 90 minutes, and decompression proceeded for 15 minutes.

Group $2 \mathrm{~S}$ rabbits were subjected to two sessions of HBOT at the weekly interval, and group $4 \mathrm{~S}$ rabbits were subjected to 4 sessions of HBOT at weekly interval.

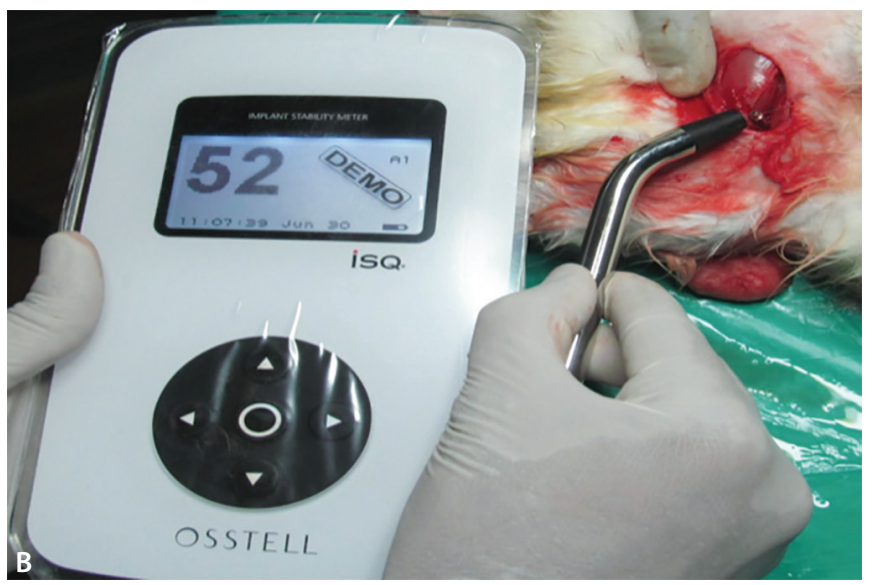

Figs 4A and B: (A) Type 49 Smart peg placed; (B) ISQ value 52 recorded using OSSTELL ISQ 
The ISQ values were recorded after one month $\left(L_{1}\right)$ and later at the end of the second month $\left(L_{2}\right)$ (Figs $6 A$ and $B$ ). The total duration of the study was 4 months from 03 March 2013 to 03 July 2013. ISQ values obtained were tabulated and subjected to statistical analysis.

\section{Results}

The results obtained were tabulated and the data was statistically analyzed using T-test and analysis of variance (ANOVA-F).

A t-test was done to compare control $(\mathrm{R})$ and test groups ( $2 \mathrm{~S}$ and $4 S$ ). At the end of 1st month, the mean of ISQ of the control

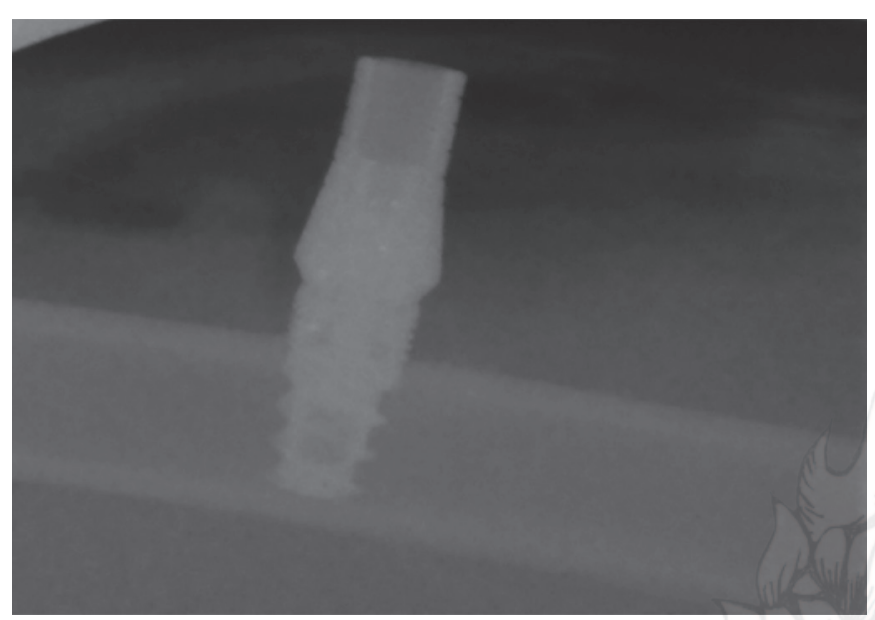

Fig. 5: Radiograph showing implant with abutment

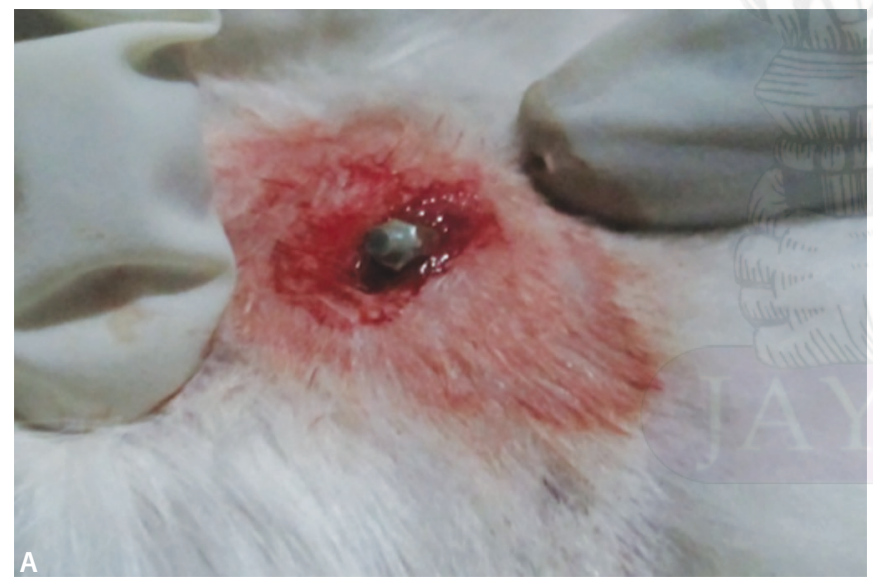

group $\left(R_{1}\right)$ was 55 , and that of the test group $\left(L_{1}\right)$ was 59.83 and $p<0.001$ (Table 1) which indicated that results were highly statistically significant. At the end of the 2 nd month, the mean of ISQ of the control group $\left(R_{2}\right)$ was 60 , and that of the test group $\left(L_{2}\right)$ was 64 and $p<0.05$ (Table 1) indicated that results were statistically significant.

On the comparison between $2 \mathrm{~S}$ and $4 \mathrm{~S}$ groups using t-test (Table 2). At the end of the 1st month, the mean of ISQ of 2S (2L1) group was 59.33 which was less than that of $4 S$ (4L1) group, i.e., 60.33 . But $p>0.05$ indicated that results were statistically not significant. $p<0.01$ with high statistical significance was found at the end of the 2 nd month with a mean of ISQ of $2 S$ (2L2) group being 61.33 which was less than that of $4 S$ (4L2), i.e., 66.67 .

Table 3 shows a comprehensive comparison between the control group $(R)$ and $2 S, 4 S$ test groups $(L)$ at the end of the first and second month. ANOVA-F statistics were applied and $p<0.001$ for test groups and was found to be highly statistically significant for all the groups.

Graph 1 shows a cumulative comparison of implant stability between control, $2 \mathrm{~S}$ and $4 \mathrm{~S}$ groups. It can be interpreted that HBOT has hastened the rate of the healing process in the $4 \mathrm{~S}$ group when compared to $2 \mathrm{~S}$ followed by control group.

\section{Discussion}

The present study was done to evaluate the effect of HBOT on the osseointegration of dental implants by determining implant stability using RFA (OSSTELL ${ }^{\circledR}$ ISQ). Results of this study revealed

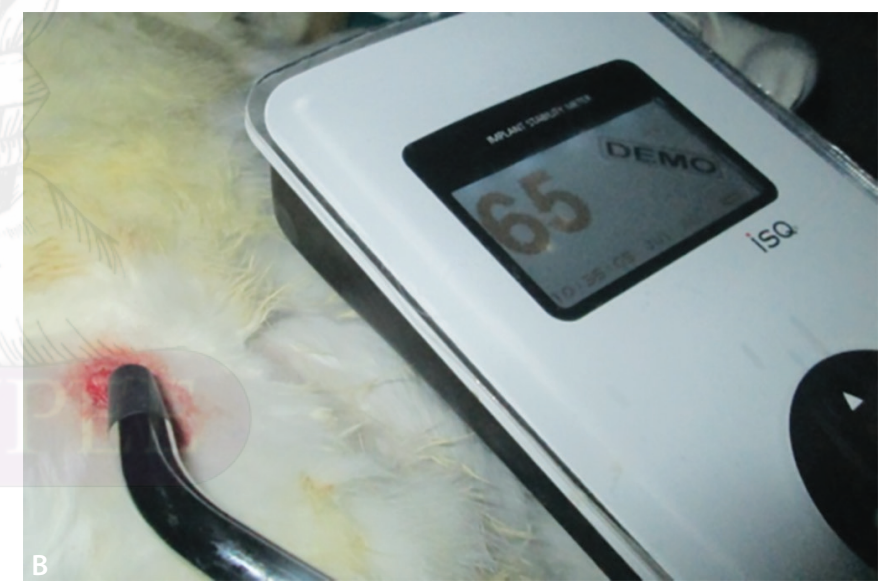

Figs $6 \mathrm{~A}$ and $\mathrm{B}$ : Follow-up ISQ values recorded

Table 1 : Comparison of control and test groups (intervention)

\begin{tabular}{|c|c|c|c|c|c|c|c|c|}
\hline \multirow[b]{3}{*}{ Group } & & \multirow[b]{3}{*}{ Sample size } & \multicolumn{6}{|c|}{ ISQ Values } \\
\hline & & & \multicolumn{2}{|c|}{ At surgery } & \multicolumn{2}{|c|}{ 1st month } & \multicolumn{2}{|c|}{ 2nd month } \\
\hline & & & Mean & $S D$ & Mean & $S D$ & Mean & $S D$ \\
\hline $\begin{array}{l}\text { Right femur of the rabbit } \\
\text { (without HBOT) }\end{array}$ & Control & 6 & (R0) 53.67 & 1.36 & (R1) 55 & 1.09 & (R2) 60 & 1.41 \\
\hline $\begin{array}{l}\text { Left femur of the rabbit } \\
\text { (with HBOT) }\end{array}$ & Intervention & 6 & (L0) 56 & 2.75 & (L1) 59.83 & 0.75 & (L2) 64 & 3.09 \\
\hline \multicolumn{2}{|l|}{ Degree of freedom } & & \multicolumn{2}{|l|}{10} & \multicolumn{2}{|l|}{10} & \multicolumn{2}{|l|}{10} \\
\hline \multicolumn{3}{|l|}{ t-statistic } & \multicolumn{2}{|c|}{1.857} & \multicolumn{2}{|c|}{8.907} & \multicolumn{2}{|c|}{2.876} \\
\hline \multicolumn{3}{|l|}{$p$ value } & \multicolumn{2}{|c|}{$>0.05$} & \multicolumn{2}{|c|}{$<0.001$} & \multicolumn{2}{|c|}{$<0.05$} \\
\hline \multicolumn{3}{|l|}{ Inference } & \multicolumn{2}{|c|}{ Not significant } & \multicolumn{2}{|c|}{ Highly significant } & \multicolumn{2}{|c|}{ Significant } \\
\hline
\end{tabular}


Table 2: Comparison between $2 \mathrm{~S}$ and $4 \mathrm{~S}$ group

\begin{tabular}{|c|c|c|c|c|c|c|c|c|}
\hline & & \multirow[b]{3}{*}{ Sample Size } & \multicolumn{6}{|c|}{ ISQ values } \\
\hline & & & \multicolumn{2}{|c|}{ At surgery } & \multicolumn{2}{|c|}{ 1st month } & \multicolumn{2}{|c|}{ 2nd month } \\
\hline \multicolumn{2}{|l|}{ Group } & & Mean & $S D$ & Mean & $S D$ & Mean & $S D$ \\
\hline $\begin{array}{l}\text { Left femur of } \\
\text { the rabbit } \\
\text { ( } 2 \text { sessions of } \\
\text { HBOT) }\end{array}$ & Control & 3 & (2L0) 56 & 3.45 & (2L1) 59.33 & 0.58 & (2L2) 61.33 & 0.58 \\
\hline $\begin{array}{l}\text { Left femur of } \\
\text { the rabbit } \\
(4 \text { sessions of } \\
\text { HBOT) }\end{array}$ & Intervention & 3 & (4L0) 56 & 2.65 & (4L1) 60.33 & 0.58 & $(4 \mathrm{~L} 2) 66.67$ & 1.52 \\
\hline Degree of freedom & & & & 4 & & 4 & & 4 \\
\hline t-statistic & & & & 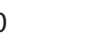 & & 21 & & 558 \\
\hline$p$ value & & & & .05 & & .05 & & .01 \\
\hline Inference & & & & nificant & Sig & ficant & Highly & gnificant \\
\hline
\end{tabular}

Table 3: Comparison control and 2S, $4 \mathrm{~S}$ interventions

\begin{tabular}{|c|c|c|c|c|c|c|}
\hline & & & \multicolumn{4}{|c|}{ ISQ values } \\
\hline & & & \multicolumn{2}{|c|}{ 1st month } & \multicolumn{2}{|c|}{ 2nd month } \\
\hline \multicolumn{2}{|l|}{ Group } & Sample size & Mean & $S D$ & Mean & $S D$ \\
\hline Right femur of the rabbit (without HBOT) & Control & 6 & 55 & 1.09 & 60 & 1.41 \\
\hline Left femur of the rabbit (with HBOT) & Intervention & 3 & 59.33 & 0.58 & 61.33 & 0.58 \\
\hline Left femur of the rabbit ( 4 sessions of HBOT) & Intervention & 3 & 60.33 & 0.58 & 66.67 & 1.52 \\
\hline Degree of sreedom & & & \multicolumn{2}{|c|}{11} & \multicolumn{2}{|c|}{11} \\
\hline (ANOVA) F-statistic & & & \multicolumn{2}{|c|}{43.926} & \multicolumn{2}{|c|}{113.426} \\
\hline$p$ value & & & \multicolumn{2}{|c|}{$<0.001$} & \multicolumn{2}{|c|}{$<0.001$} \\
\hline Inference & & & \multicolumn{2}{|c|}{ Highly significant } & \multicolumn{2}{|c|}{ Highly significant } \\
\hline
\end{tabular}

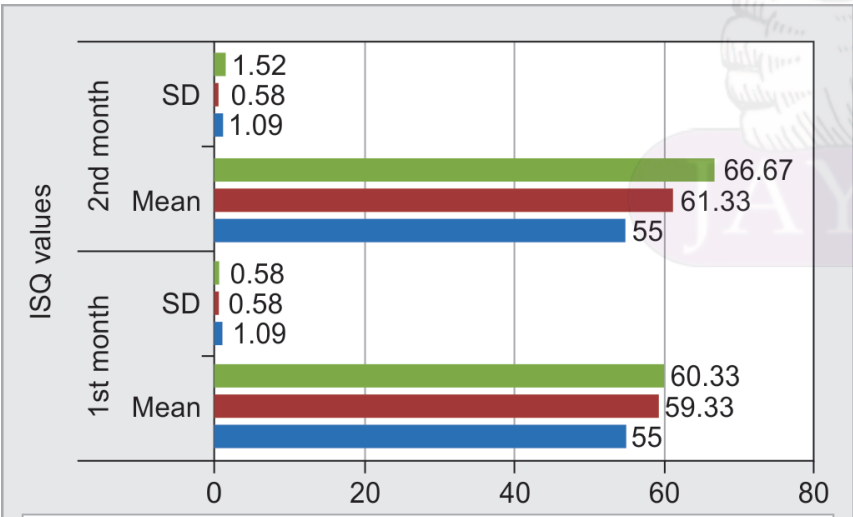

Left leg (with 4 sessions of HBOT) $\square$ Right leg (without HBOT) - Left leg (with 2 sessions of HBOT)

Graph 1:. Comparison of healing process of control, $2 \mathrm{~S}, 4 \mathrm{~S}$ groups

that HBOT therapy has significantly hastened osseointegration and implant stability was found to be improved.

The selection of rabbits for this study preceded reviewing of the available literature. The rabbit is one of the most commonly used animals, being used in approximately $35 \%$ of musculoskeletal research studies due to ease of handling and size. ${ }^{10}$ They reach sexual, skeletal maturity at around 6 months of age ${ }^{11}$ and similarities were found in the bone mineral density (BMD) and subsequently the fracture toughness of mid-diaphyseal bone between rabbits and humans. ${ }^{12}$

HBOT was first documented in 1662 when Henshaw built the first hyperbaric chamber or 'domicilium. In 1927, Cunningham reported improvement in circulatory disorders at sea level and deterioration at altitude. A patient grateful to Cunningham built 'steel ball hospital chamber. ${ }^{6} \mathrm{R}$ Marx created a specific hyperbaric oxygen therapy protocol for the prophylactic treatment of osteoradionecrosis of the jaw before dental procedures. The use of this therapy is considered to be a standard of care by many dentists and hyperbaric physicians. ${ }^{13}$

Hyperbaric oxygen therapy is defined by the undersea and hyperbaric medical society (UHMS) as a treatment in which a patient intermittently breathes $100 \%$ oxygen while the treatment chamber is pressurized to a pressure greater than sea level. ${ }^{14}$ Originally developed for the treatment of decompression sickness, HBOT is primarily an adjunctive treatment for the management of select non-healing wounds. This treatment is proven effective for a number of different medical and surgical conditions either as a primary or adjunctive treatment. It is also used to treat many other medical conditions that are still considered experimental by the mainstream medical establishment-despite decades of reported benefit.

Although the number of indications for hyperbarics may be quite large, the mechanisms of therapy are few. HBOT is believed to (1) enhance perfusion, (2) stimulate angiogenesis, (3) supersaturate the bloodstream with oxygen, (4) act as a bactericide, and (5) prevent the 
production of alpha toxin. The theories supporting these mechanisms are based on fundamental principles of medicine and physics.

Radiographic analysis (2001) and histomorphometric analysis (2008) of bone in rabbits showed that maximum amount of lamellar bone was formed around 4-5 weeks of the osteotomy. ${ }^{15}$ Based on these studies the present study was limited to a period of 2 months for each group.

The mean of ISQ values of L1 was 59.83 at the end of the 1st month which was more than that of R1 (55) which was statistically highly significant $(p<0.001)$. At the end of 2 nd month mean of ISQ for L2 was 64 and that of $\mathrm{R} 2,60$ and results were statistically significant $(p<0.05)$

The improved ISQ values for $L_{1}$ and $L_{2}$ groups may be due to the effect of HBOT on enhancing wound healing. The results of present study support earlier studies of peter Nillson et al. that HBOT promotes wound healing by collagen formation and fibroblastic proliferation. ${ }^{14,16}$

Comparing the test groups, $2 \mathrm{~S}$, and $4 \mathrm{~S}$ (Table 2), At the end of the 1st month, though the mean of ISQ of $2 \mathrm{~S}, 2 \mathrm{~L}_{1}$ being 59.33 which is less than that of $4 \mathrm{~S}, 4 \mathrm{~L}_{1}$ being 60.33 the results were statistically insignificant $(p>0.05)$. At the end of the 2 nd month the mean of ISQ of $2 \mathrm{~S}, 2 \mathrm{~L}_{2}$ was 61.33 which was less than that of $4 \mathrm{~S}, 4 \mathrm{~L}_{2}$ being 66.67 with high statistical significance $(p<0.001)$ indicating that 4 HBOT sessions were more effective when compared to 2 sessions of HBOT.

An overall comparison of ISQ values between control (right femur) and test groups $(2 \mathrm{~S}, 4 \mathrm{~S})$ was done in Table 3 . Results revealed that implant stability was found to be improved with the HBOT in all the test groups. The mean ISQ of group 4S was found to be more among all the groups (Graph 1).

Results of the present study were supporting previous studies by Nilsson et al., which showed that HBOT treatment caused a significant increase of bone formation in the implants, and histology demonstrated has a marked effect on healing and remodeling processes of bone tissue. ${ }^{17}$ Granstrom et al., ${ }^{18}$ evaluated the biological effects on oral tissues by hyperbaric treatment and proved that the periosteum of compact bone and mineral content increased. Giblin et al., ${ }^{19}$ concluded that the $\mathrm{O}_{2}$ available in HBOT therapy was able to diffuse through membranes which explains the mechanism of action of the proposed hyperbaric oxygen therapy. Ueng et al., ${ }^{20}$ proposed that hyperbaric oxygen (HBOT) therapy has been shown to enhance bone, muscle, skin, and wound healing, particularly in conditions of ischemia and low oxygen tension.

The results of the present study are consistent with the previous studies. Based on all these previous studies we can conclude that HBOT has a significant effect on healing and can hasten the osseointegration.

\section{LIMITATIONS OF THE STUDY}

- Slight variations might be experienced when tested in humans due to differences in microstructural composition and physiology of bone healing.

- The study was conducted in the femur of rabbits, and mild variations may be encountered with human jaw bone (maxilla and mandible) due to the difference in bone architecture.

- Limited sample size.

- The number and frequency of HBOT sessions were limited.

- The histological and radiological analysis was not done. Nevertheless, the present study provides information on the effect of HBOT on bone formation-osseointegration, RFA.

\section{Conclusion}

This in vivo study indicated that HBOT therapy has a promotive effect on the rate of osseointegration of implants. The minimum number of sessions required to obtain a significant improvement was found to be 4 .

\section{Clinical significance}

This study opens a new scope for further in vivo research in utilizing HBOT and RFA in implant surgeries. It provides a proper understanding of implant stability and the method by which HBOT improves the same. Application of HBOT and RFA in case of the maxillofacial prosthesis, irradiated patients can also be experimented taking the present study as a baseline data.

\section{References}

1. Palmer R. Introduction to dental implants. Br Dent J 1999;187(3):127132.

2. Branemark PI, Hansson BO, Adell R, et al. Osseointegrated implants in the treatment of the edentulous jaw. Experience from a 10-year period. Scand J Plas Reconst Surg 1977;16:1-132.

3. Adell R, Lekholm U, Rockler B, et al. A 15 year study of osseointegrated implants in the treatment of the edentulous jaw. Int J Oral Surg 1981;10:387-416.

4. Albrektsson et al. Basics of osseointegration. Acta Orthopaedica Scand. 1981;52:168-169.

5. Gapski R, Wang HL, Mascarenhas $P$, et al. Critical review of immediate implant loading. Clin Oral Imp Res 2003;14:515-27.

6. Cunningham OJ. Oxygen therapy by means of compressed air. AnaestAnalg. 1927;6:64.

7. Bonomo SR, Davidson JD, Tyrone JW, et al. Enhancement of wound healing by hyperbaric oxygen and transforming growth factor in a new chronic wound model in aged rabbits. Arch Surg 2000;135(10):1148-1153.

8. Zhang X, Torcasio A, Vandamme K, et al. Enhancement of Implant Osseointegration by High-Frequency Low-Magnitude Loading. PloS One 2012;7(7):e40488.

9. Meredith N, Books K, Fribergs B, et al. Resonance frequency measurements of implant stability in vivo. A cross-sectional and longitudinal study of resonance frequency measurements on implants in the edentulous and partially dentate maxilla. Clin Oral Implants Res 1997;8:226-233.

10. Herrero-Climent $M$, Albertini M, et al. Resonance frequency analysisreliability in third generation instruments: Osstell mentor. Med Oral Patol Oral Cir Bucal 2012;17(5):801-806.

11. Neyt JG, Buckwalter JA, Carroll NC. Use of animal models in musculoskeletal research. lowa Orthop J 1998;18:118-123.

12. Gilsanz V, Roe TF, Gibbens DT, et al. Effect of sex steroids on peak bone density of growing rabbits. Am J Physiol 1988;255:416-421.

13. Wang X, Mabrey JD, et al. An interspecies comparison of bone fracture properties. Biomed Mater Eng 1998;8:1-9.

14. Marx RE, Johnson RP, Kline SN. Prevention of osteoradionecrosis: a randomized prospective clinical trial of hyperbaric oxygen versus penicillin. J Am Dent Assoc 1985;111(1):49-54.

15. Hampson NB. ed Hyperbaric Oxygen Therapy; 1999 committee report, Kensington MD, undersea and Hyperbaric Medical Society. 1999.

16. Matos MA, Araújo FP, Paixão FB. Histomorphometric evaluation of bone healing in rabbit fibular osteotomy model without fixation. J Orthop Surg Res 2008;3:4.

17. Nilsson P, Albrektsson T, Granström G, et al. The Effect of Hyperbaric Oxygen Treatment on Bone Regeneration: An Experimental Study Using the Bone. Harvest Chamber in the Rabbit. Int J Oral Maxillofac Implants 1988;3:43-48.

18. Granström G, Magnusson BC, Nilsson LP, et al. Biological effects on oral tissues by hyperbaric oxygen treatment, EUBS1989.

19. Giblin FJ, Schrimscher L, Chakrapani B, et al. Exposure of Rabbit Lens to Hyperbaric Oxygen InVitro: Regional Effects on GSH Level Investigative Ophthalmol Visual Sci 1988;29(8):154-156.

20. Ueng SW, Lee MS, Tai CL, et al. Hyperbaric oxygen therapy improves medial collateral ligament healing in a rabbit model. Formos J Musculoskelet Disorder 2011;2(1):7-11. 